\title{
Cervical spinal canal compromise in a 14-year-old girl with hereditary multiple exostoses
}

\author{
Amar Patel • Mihir M. Thacker
}

Received: 5 April 2010 /Revised: 11 May 2010 / Accepted: 2 June 2010 / Published online: 26 June 2010

(C) Springer-Verlag 2010

This report highlights the importance of advanced imaging in the case of a 14-year-old-girl with multiple hereditary exostoses who presented with painful restriction of neck motion. CT scans show an osteochondroma arising from the posterior elements of $\mathrm{C} 2$ causing cord compression (Fig. 1).

Multiple hereditary exostoses is an autosomal-dominant disorder characterized by the development of multiple cartilage-capped lesions in rapidly growing bone. The cervical spine represents $80 \%$ of spine involvement with C2 being the most commonly affected vertebra [1]. Most osteochondromas arise from the posterior elements of the vertebra and do not encroach on the spinal canal. A recent study reported a $68 \%$ prevalence of spinal involvement with $27 \%$ having lesions encroaching on the spinal canal in 44 patients with multiple hereditary exostoses [2]. Some patients may develop acute neurological deficits. A treating physician's awareness of this high prevalence is essential.

\section{References}

1. Moon KS, Lee JK, Kim YS et al (2006) Osteochondroma of the cervical spine extending multiple segments with cord compression. Pediatr Neurosurg 42:304-307

2. Roach JW, Klatt JW, Faulkner ND (2009) Involvement of the spine in patients with multiple hereditary exostoses. J Bone Joint Surg 91:1942-1948

\footnotetext{
A. Patel $\cdot$ M. M. Thacker $(\bowtie)$

Department of Orthopaedic Surgery,

Alfred I. duPont Hospital for Children,

1600 Rockland Road,

Wilmington, DE 19803-3607, USA

e-mail: mthacker@nemours.org
}

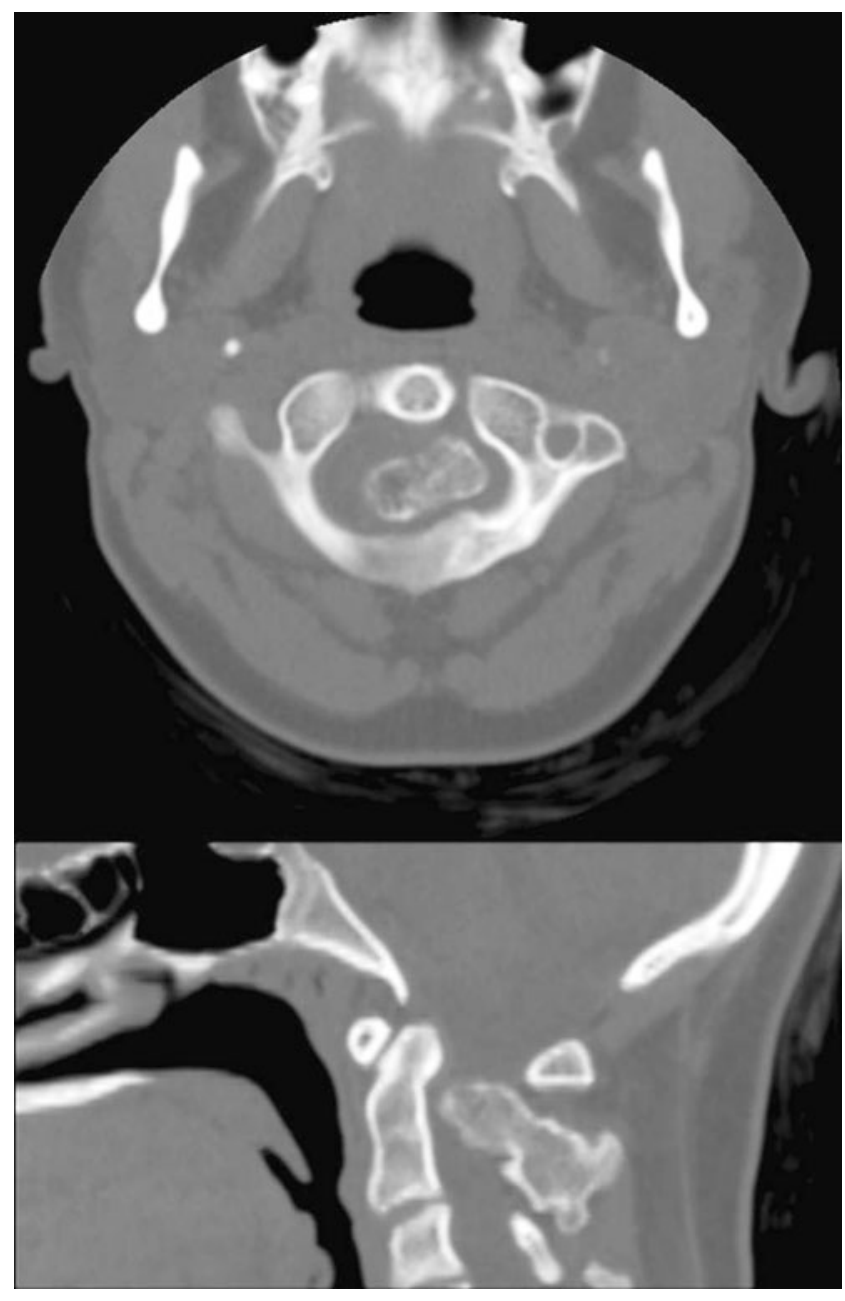

Fig. 1 CT scans (axial and sagittal cuts) 